\title{
Absence of Neisseria meningitidis from Throat Swabs of Kuwaiti Pilgrims after Returning from the Hajj
}

\author{
Entesar H. Husain ${ }^{\text {a }}$ Ali A. Dashti ${ }^{\text {b }}$ Qudsiya Y. Electricwala ${ }^{\text {b }}$ \\ AbdulSamad M. AbdulSamad $^{c}$ Safeya Al-Sayegh ${ }^{d}$ \\ a Department of Pediatrics, Faculty of Medicine, ${ }^{b}$ Medical Laboratory Sciences, Faculty of Allied Health, \\ 'Department of Surgery, Amiri Hospital, and d Department of Family Medicine, Quadsiya Family Medicine Center, \\ Kuwait
}

\section{Key Words}

Ciprofloxacin - Meningococcal disease $\cdot$ Neisseria

meningitidis $\cdot$ Quadrivalent meningococcal vaccine

\begin{abstract}
Objective: To investigate whether or not Neisseria meningitidis was present in the throat of Kuwaiti pilgrims after returning from the Hajj. Method: Throat swabs were taken from 177 participants 1 week after returning from the Hajj. The participants were asked about: associated medical conditions, meningococcal vaccination status and the intake of ciprofloxacin before leaving Mecca for Kuwait. Results: There was no throat colonization with $N$. meningitidis on any of the throat swabs. Of the 177 pilgrims, 163 (92\%) were vaccinated with meningococcal quadrivalent vaccine before leaving to Saudi Arabia. Ninety-seven of the pilgrims (83\%) had received one dose of ciprofloxacin before leaving Mecca. Conclusion: The result showed that vaccination before leaving Kuwait and ciprofloxacin prophylaxis were effective in preventing throat colonization with Neisseria meningitidis.

Copyright $\odot 2010$ S. Karger AG, Basel
\end{abstract}

\section{Introduction}

Each year during the Hajj, approximately 3 million people from more than 140 countries worldwide gather in Mecca and Medina in Saudi Arabia. Meningococcal disease outbreaks have been reported during the Hajj due to overcrowding and close person-to-person contact [1]. Nasopharyngeal carriage is the primary source of further transmission and hence reported outbreaks [2]. To prevent further outbreaks, the health authorities in Saudi Arabia have implemented compulsory vaccination with the quadrivalent meningococcal vaccine to all pilgrims since 2001 [3]. This was coupled with compulsory administration of oral ciprofloxacin to pilgrims coming from the sub-Saharan African belt in attempt to reduce the meningococcal carriage rate.

The last meningococcal outbreak associated with the return of pilgrims was in 2000 and was associated with serotype W-135 [4]. In order to prevent further outbreaks, the Department of Public Health and Preventive Medicine at the Ministry of Health in Kuwait, in accord with Saudi officials, had implemented the administration of quadrivalent meningococcal vaccine to all pilgrims at least 10 days prior to leaving for Mecca and the adminis-

Dr. Entesar H. Husain

Department of Pediatrics, Faculty of Medicine PO Box 24923

Safat 13110 (Kuwait)

Fax +965 2533 8940, E-Mail entesar@qualitynet.net 
tration of one dose of oral ciprofloxacin to all Kuwaiti pilgrims at least 1 day before returning to Kuwait.

There are various data about the Neisseria meningitidis carriage rate in returning pilgrims in various countries $[5,6]$, but data about Kuwaiti pilgrims are not available in the literature. Therefore, we conducted this study to investigate whether or not $N$. meningitidis was present in the throat of Kuwaiti pilgrims after returning from Saudi Arabia.

\section{Subjects and Method}

The study was conducted prospectively on returning Hajj pilgrims 7 days after arrival from Mecca in January 2005. One hundred and seventy-seven pilgrims who attended a post-Hajj gathering had participated in a questionnaire survey that included the following questions: underlying health conditions, symptoms of upper respiratory tract infection either during the Hajj or after returning to Kuwait, and a history of ciprofloxacin intake 1 day prior to their return. Personal vaccination cards were verified for meningococcal polysaccharide vaccine and influenza vaccine and their dates.

After giving consent, swabs were taken from both tonsils and the pharyngeal wall using a standard technique. They were transferred to the bacteriology laboratory within 2-3 h after collection. Swabs were cultured onto chocolate agar prepared using GC agar base (Oxoid, UK) plus 5\% yeast extract (Acumedia, USA), 5\% blood (defibrinated sheep blood; Saudi Prepared Media Lab, Saudi Arabia) and 1 vial of VCN selective supplement. Plates were immediately incubated in a $\mathrm{CO}_{2}$ jar for $48 \mathrm{~h}$.

Gram stain and oxidase test were performed on all colonies isolated. All oxidase-positive isolates were subcultured onto chocolate agar and incubated in a $\mathrm{CO}_{2}$ jar for $48 \mathrm{~h}$. Bacterial isolates were identified by the API NH (bioMérieux, France) and results were confirmed by carbohydrate utilization tests in cystine trypticase agar with $1 \%$ dextrose, maltose, sucrose and lactose (bioMérieux).

Data entry, processing and analysis were done using the Statistical Package for Social Sciences (SPSS for Windows, version 10.0).

\section{Results}

Of the 177 participants, 104 were females and 73 males. Their mean age was $37 \pm 11.5$ years and their median age was 38 years. Their mean stay in Mecca lasted 7 days. Of the 177 participants, 28 (16\%) had an underlying chronic disease (hypertension: 11 patients; diabetes mellitus: 15, and bronchial asthma: 2); 163 (92\%) were vaccinated with meningococcal polysaccharide vaccine and 140 (79\%) with influenza vaccine prior to their travel to the Hajj (median: 11 days before). Ciprofloxacin prophylaxis was taken by 97 (83\%) of the participants. Of the 177 participants, approximately 50\% reported upper respiratory symptoms during the Hajj events while 117 (66\%) fell ill with respiratory symptoms after returning to Kuwait.

There were 72 positive throat swab cultures, of which $43(60 \%)$ showed a negative Gram stain reaction. Only Gram-negative isolates were further identified by API $\mathrm{NH}$ reaction. There were 4 isolates which were identified by the API NH as Neisseria species but none of the cultured throat swabs had grown N. meningitidis.

\section{Discussion}

N. meningitidis carriage rates are indicative of a potential meningococcal outbreak. In Kuwait, various measures were undertaken to ensure the reduction of the incidence of meningococcal carriage and hence the disease. First, a meningococcal quadrivalent vaccine was introduced as part of the routine childhood immunization schedule in 1991. Furthermore, all Hajj pilgrims are requested to be vaccinated with meningococcal polysaccharide vaccine before going to Saudi Arabia. Oral ciprofloxacin is given to all returning pilgrims regardless of their vaccination status.

In this study, we documented the absence of N. meningitidis from throat swabs of 177 Kuwaiti pilgrims, similar to a report among 123 Iranian pilgrims [7]. It is likely that both the high vaccination rate and the high percentage of oral ciprofloxacin intake contributed to our finding. Furthermore, our study was conducted in 2005, which was a non-outbreak season. Wilder-Smith et al. [5] had reported a carrier rate of serogroup W-135 in 1.3\% of 193 Malay pilgrims in 2002 in contrast to a 15\% carriage rate among pilgrims in 2001, which was an outbreak season. A very low colonization rate of $3 \%$ was detected during the 2003 Hajj season among 344 pilgrims of 29 nationalities [6]. In our current study, we have not documented the rate of colonization with Neisseria meningitidis before leaving Saudi Arabia to Kuwait. Further studies are needed to look into the colonization rates in Kuwait returnees from the Hajj.

\section{Conclusion}

During a non-outbreak year, the current public health measures were effective in preventing meningococcal carrier status from Kuwaiti returnees from the Hajj. In the presence of a meningococcal outbreak, continuous surveillance for meningococcal carriage is needed. 


\section{References}

-1 Al-Gahtani YM, El Bushra HE, Al-Qarawi SM, Al-Zubaidi AA, Fontaine RE: Epidemiological investigation of an outbreak of meningococcal meningitis in Makkah, Saudi Arabia, 1992. Epidemiol Infect 1995;115: 399-409.

-2 Rosenstein NE, Perkins BA, Stephens DS, Popovic T, Hughes JM: Meningococcal disease. N Engl J Med 2001;344:1378-1388.

3 Memish ZA: Meningococcal disease and travel. Clin Infect Dis 2002;34:84-90.
4 Fine A, Layton M, Hakim A: Serogroup W-135 meningococcal disease among travelers returning from Saudi Arabia - United States, 2000. MMWR Morb Mortal Wkly Rep 2000;49:345-346.

5 Wilder-Smith A, Barkham TMS, Chew SK, Paton NI: Absence of Neisseria meningitidis W-135 electrophoretic type 37 during the Hajj, 2002. Emerg Infect Dis 2003;10:734737.
6 Balkhy $\mathrm{HH}$, Memish ZA, Almuneef MA, Osoba AO: Neisseria meningitidis W-135 carriage during the Hajj season 2003. Scand J Infect Dis 2004;36:264-268.

7 Alborzi A, Oskoee S, Pourabbas B, Alborzi S, Astaneh B, Gooya MM, Kaviani MJ: Meningococcal carrier rate before and after Hajj pilgrimage: effect of single dose ciprofloxacin on carriage. East Mediterr Health J 2008; 14:277-282. 